\title{
SOCIOECONOMIC INDICATORS AND RISK OF LUNG CANCER IN CENTRAL AND EASTERN EUROPE
}

\author{
Františka Hrubá ${ }^{1}$, Eleonóra Fabiánová ${ }^{1}$, Vladimír Bencko², Adrian Cassidy ${ }^{3}$, Jolanta Lissowska ${ }^{4}$, Dana Mates ${ }^{5}$, \\ Péter Rudnai ${ }^{6}$, David Zaridze ${ }^{7}$, Lenka Foretová ${ }^{8}$, Vladimír Janout ${ }^{9}$, Neonilia Szeszenia-Dabrowska ${ }^{10}$, \\ Paul Brennan ${ }^{11}$, Paolo Boffetta ${ }^{11}$ \\ ${ }^{1}$ Regional Authority of Public Health, Banska Bystrica, Slovakia \\ ${ }^{2}$ Institute of Hygiene and Epidemiology, First Faculty of Medicine, Charles University, Prague, Czech Republic \\ ${ }^{3}$ Roy Castle Lung Cancer Research Programme, University of Liverpool Cancer Research Centre, University of Liverpool, United Kingdom \\ ${ }^{4}$ Cancer Center and M.Sklodowska-Currie Institute of Oncology, Warsaw, Poland \\ Institute of Public Health, Bucharest, Romania \\ ${ }^{6}$ National Institute of Environmental Health, Budapest, Hungary \\ ${ }^{7}$ Cancer Research Centre, Moscow, Russia \\ ${ }^{8}$ Masaryk Memorial Cancer Institute, Brno, Czech Republic \\ ${ }^{9}$ Faculty of Medicine, Palacky University, Olomouc, Czech Republic \\ ${ }^{10}$ Institute of Occupational Medicine, Lodz, Poland \\ ${ }^{11}$ International Agency for Research on Cancer, Lyon, France
}

\section{SUMMARY}

Background: Social inequalities have been shown to contribute to the risk of lung cancer in industrialized countries, but it is unclear whether they also play a role in former socialist countries of Europe.

Methods: A case-control study involving 3,403 cases and 3,670 controls was conducted in Central European countries (Czech Republic, Hungary, Poland, Romania, Slovakia), Russia, and in the UK. Indicators of socioeconomic status, including education and white/blue collar occupation based on lifetime occupations were analysed as indicators of risk factors for lung cancer development, after adjustment for tobacco smoking and exposure to occupational carcinogens.

Results: Both indicators of socioeconomic status: low education and blue collar occupations were found as significant risk factors for lung cancer in men. The odds ratio of lung cancer for blue collar occupations compared to white collar occupations was 1.37 (95\% confidence interval 1.15-1.62), that for low education compared to high education (analysis restricted to Central European countries) was 1.35 (95\% confidence interval 1.03-1.77). No such effects were observed in women.

Conclusions: The confirmation of the significant inverse association between the indicators of socioeconomic status and lung cancer risk in men may serve as a strong incentive for adoption of occupational and public health measures in lung cancer prevention.

Key words: lung cancer, socioeconomic status, indicators, white/ blue collar occupation, education

Address for correspondence: F. Hrubá, Regional Authority of Public Health, Cesta k nemocnici 1, 97556 Banská Bystrica, Slovakia. E-mail: hruba@vzbb.sk

\section{INTRODUCTION}

In the former socialist Central European countries, many common diseases remain more prevalent than in the developed industrialized countries - cardiovascular diseases, cancer in general and lung cancer in particular. Cancer of the trachea, bronchus and lung is a major component of cancer mortality (1). The cumulative risk of developing lung cancer in these countries is among the highest in the world, being currently around 10\% among men by the age of 75 (2).

In industrialized countries, male lung cancer risk shows a negative gradient by socioeconomic status, particularly in recent decades. A systematic review reported a negative mortality trend in 34 male populations compared with 6 positive trends, and paral- leled by 13 negative gradients in incidence (3). Since time of the review, other studies confirmed this gradient as well (4-11). In women, the patterns are less consistent $(3,8-10)$. Little is known on the social class effect in former socialist countries.

The goal of this article is to investigate association between two available indicators of socioeconomic status (education and white/blue collar occupation) and risk of lung cancer development in seven European countries, including five former socialist countries from Central Europe and Russia. Main hypothesis is, that higher lung cancer risk is associated with low education and blue collar occupations. The investigation takes into account the two factors which may be responsible for the effect of socioeconomic status indicators on lung cancer risk: tobacco smoking and exposure to occupational carcinogens $(4,9,12,13)$. 


\section{MATERIAL AND METHODS}

A hospital based case-control study was conducted in 16 areas of seven countries: Brno, Olomouc, and Prague (Czech Republic), Borsod, Budapest, Heves, Szabolcs, and Szolnok (Hungary), Lodz, and Warsaw (Poland), Bucharest (Romania), Moscow (Russia), Banska Bystrica, Bratislava, and Nitra (Slovakia), Liverpool (United Kingdom). In each area, newly diagnosed, histologically or cytologically confirmed cases of primary lung cancer were recruited during 1998-2001 together with controls frequency-matched by sex and age. The selection criteria for cases were residence in the study area for at least one year prior to diagnosis, and age lower than 75 . Hospital based controls were selected in most centres among patients admitted to the same hospitals of the cases or general hospitals serving the study areas for diseases other than cancer or tobacco-related. In Liverpool and Warsaw, population based controls were selected from population or general practitioner registries. Both cases and controls were interviewed using a standardized questionnaire which consisted of questions about residential history, tobacco smoking, diet, medical history, as well as occupational history. The latter included collection of detailed information on each job held by study subjects in a chronological order, which was used to assess exposure to 70 known and potential occupational lung carcinogens.

For the socioeconomic status, two indicators of socioeconomic status were studied: an occupation-based classification, and education. The occupation-based indicator was derived from the

Annex 1: Construction of the occupation-based indicator of socioeconomic status by ISCO code from 1968

\begin{tabular}{|c|c|}
\hline ISCO code & Description \\
\hline \multicolumn{2}{|l|}{ White collar } \\
\hline 0,1 & Professional, technical and related workers \\
\hline 2 & Administrative and managerial workers \\
\hline 3 & Technical, health, pedagogical workers \\
\hline $4.0-4.4$ & Clerical and related workers \\
\hline 5.0 & Managers (sales and services) \\
\hline 6.0 & Farm managers and supervisors \\
\hline 7.0 & Production supervisors \\
\hline \multicolumn{2}{|l|}{ Blue collar } \\
\hline $4.5-4.9$ & \\
\hline $5.1-5.9$ & Sales and service workers \\
\hline $6.1-6.4$ & Agriculture, animal, forestry workers \\
\hline $7.1-7.9,8,9$ & Production workers \\
\hline \multicolumn{2}{|l|}{ Inactive period } \\
\hline 00001 & Military service \\
\hline 00002 & Unemployed \\
\hline 00003 & Retirement \\
\hline 00004 & Student \\
\hline 00005 & Homekeeping \\
\hline 00006 & Chronic illness \\
\hline 00007 & Prisoner \\
\hline
\end{tabular}

lifetime occupational history, where ISCO codes from 1968 (14) were used to distinguish between white and blue collar occupations, and to record an inactive period for each individual job. Professional, technical, managerial, administrative occupations and property owners were categorized as white collar jobs. Shopping, services, craft, agriculture and industry manual occupations were categorized as blue collar jobs. Military service, retirement, study, household, long-term disablement, and arrest were taken as the inactive periods (Annex 1). Overall, study participants with employment in blue collar occupations for more than two thirds of their total occupational history (ignoring inactive periods) were categorized as blue collar workers (and similarly white collar workers). The remaining study participants were treated as a mixed group. Education was classified in three categories: low (up to completion of elementary school), middle (apprentice and secondary school) and high (higher than secondary school).

Odds ratios (OR) for risk of lung cancer development and 95\% confidence intervals (CI) were derived from unconditional logistic regression models. All models were fitted separately for men and women, because previous studies had indicated different association between socioeconomic status and lung cancer according to gender (13). In the analysis by education, data from Liverpool were excluded, due to very different education system in the United Kingdom as compared to Central European countries. Regression models included country, age (4 categories: less than 50, 50-59, 60-69, 70 and more), tobacco smoking and occupational exposure to carcinogens. Tobacco smoking variables represented a cumulative tobacco consumption expressed as pack years (1 pack year is defined as 20 manufactured cigarettes smoked per day for 1 year) in categories $(0,<=18,<=33$, more than 33$)$ and type of cigarettes smoked (filter, non-filter, hand-rolled); never smokers were considered those who smoked less than 100 cigarettes during entire life. Occupational exposure to carcinogens was expressed as a binary variable, representing exposure ever to at least one of the following agents: inorganic insulation dust, arsenic, abrasives dust, silica, carbon black, wood dust, chromate dust, cadmium, and polycyclic aromatic hydrocarbons. All statistical analyses were performed using the Stata software (15).

\section{RESULTS}

Out of 3,403 eligible lung cancer cases, 542 (15.9\%) and out of 3670 eligible controls, 550 (15.0\%) were not included in the study. As for cases, 27 were discharged from hospital before the interview, 53 were too ill to be interviewed, 13 had died before the interview and 449 refused to participate. In case of controls, out of 550 not included 16 were discharged from hospital before the interview, 21 were too ill to be interviewed, 2 died before the interview and 511 refused to participate. The study population included in the analysis comprised 2,861 cases and 3,118 controls, the analysis of education included 2,633 cases and 2,884 controls.

Table 1 shows the distribution of lung cancer cases and the control group according to sex, country, age, smoking status and socioeconomic indicators. There was no difference in age (mean age in men, 60.8 years in cases and 60.6 years in controls; in women, 59.9 years in cases and 60.1 years in controls). As expected, there was a higher percentage of smokers in both men and 
Table 1. Distribution of socioeconomic status indicators and other characteristics in lung cancer cases and controls by gender

\begin{tabular}{|c|c|c|c|c|c|c|}
\hline & \multicolumn{3}{|c|}{ CASE } & \multicolumn{3}{|c|}{ CONTROL } \\
\hline & Men & Women & Total & Men & Women & Total \\
\hline \multicolumn{7}{|l|}{ Center } \\
\hline Czech Republic & 235 & 69 & 304 & 323 & 171 & 494 \\
\hline Hungary & 315 & 87 & 402 & 266 & 65 & 331 \\
\hline Poland & 557 & 243 & 800 & 581 & 266 & 847 \\
\hline Romania & 141 & 40 & 181 & 169 & 89 & 258 \\
\hline Russia & 521 & 79 & 600 & 521 & 79 & 600 \\
\hline Slovakia & 288 & 58 & 346 & 294 & 60 & 354 \\
\hline$U^{*}$ & 148 & 80 & 228 & 151 & 83 & 234 \\
\hline Total & 2205 & 656 & 2861 & 2305 & 813 & 3118 \\
\hline \multicolumn{7}{|l|}{ Age } \\
\hline$<50$ & 262 & 124 & 386 & 313 & 140 & 453 \\
\hline 50-59 & 672 & 176 & 848 & 687 & 224 & 911 \\
\hline $60-69$ & 872 & 225 & 1097 & 864 & 269 & 1133 \\
\hline $70+$ & 399 & 131 & 540 & 441 & 180 & 621 \\
\hline \multicolumn{7}{|l|}{ Smoking } \\
\hline Non smoker & 48 & 176 & 224 & 535 & 505 & 1040 \\
\hline$<=18$ pack-years & 185 & 118 & 303 & 543 & 157 & 700 \\
\hline 18-33 pack-years & 616 & 174 & 790 & 558 & 96 & 654 \\
\hline >33 pack years & 1346 & 186 & 1532 & 650 & 91 & 701 \\
\hline \multicolumn{7}{|l|}{ Occupation } \\
\hline White collar & 489 & 316 & 805 & 764 & 401 & 1165 \\
\hline Mixed group & 157 & 56 & 213 & 161 & 57 & 218 \\
\hline Blue collar & 1550 & 275 & 1825 & 1372 & 342 & 1714 \\
\hline Missing & 9 & 9 & 18 & 8 & 13 & 21 \\
\hline \multicolumn{7}{|l|}{ Education* } \\
\hline Low & 374 & 128 & 502 & 292 & 153 & 445 \\
\hline Middle & 1395 & 340 & 1735 & 1403 & 450 & 1853 \\
\hline High & 283 & 107 & 390 & 455 & 125 & 580 \\
\hline Missing & 5 & 1 & 6 & 4 & 2 & 6 \\
\hline
\end{tabular}

* UK is not included in the analysis of education

Table 2. Distribution of smoking status (\%) according to socioeconomic status indicators in controls

\begin{tabular}{|c|c|c|c|c|c|c|c|c|}
\hline & \multicolumn{4}{|c|}{ MEN } & \multicolumn{4}{|c|}{ WOMEN } \\
\hline & Never smoker & $\begin{array}{c}\text { Pack-years } \\
\leq 18\end{array}$ & $\begin{array}{c}\text { Pack-years } \\
>18 \& \text { pack- } \\
\text { years } \leq 33\end{array}$ & $\begin{array}{c}\text { Pack-years } \\
>33\end{array}$ & Never smoker & $\begin{array}{l}\text { Pack-years } \\
\leq 18\end{array}$ & $\begin{array}{l}\text { Pack-years } \\
>18 \& \text { pack- } \\
\text { years } \leq 33\end{array}$ & $\begin{array}{c}\text { Pack-years } \\
>33\end{array}$ \\
\hline \multicolumn{9}{|l|}{ Occupation } \\
\hline White collar & 28.6 & 26.2 & 22.8 & 22.4 & 61.7 & 21.0 & 11.5 & 5.8 \\
\hline Mixed group & 25.8 & 23.3 & 19.5 & 31.4 & 47.4 & 29.8 & 14.0 & 8.8 \\
\hline Blue collar & 20.3 & 22.4 & 26.0 & 31.3 & 65.3 & 16.2 & 12.0 & 6.5 \\
\hline$p$-value & $<0.001$ & & & & 0.169 & & & \\
\hline \multicolumn{9}{|l|}{ Education } \\
\hline High & 31.2 & 35.8 & 17.8 & 15.2 & 63.7 & 17.7 & 10.5 & 8.1 \\
\hline Middle & 20.8 & 35.2 & 25.4 & 18.6 & 59.6 & 22.7 & 13.5 & 4.2 \\
\hline Low & 25.3 & 25.7 & 20.9 & 28.1 & 79.4 & 9.3 & 6.0 & 5.3 \\
\hline$p$-value & $<0.001$ & & & & $<0.001$ & & & \\
\hline
\end{tabular}


Table 3. Association between socioeconomic status indicators and risk of lung cancer

\begin{tabular}{|c|c|c|c|c|}
\hline & MEN & & & \\
\hline & $\mathrm{OR}^{\mathrm{a}}(95 \% \mathrm{Cl})$ & $\mathrm{OR}^{\mathrm{b}}(95 \% \mathrm{Cl})$ & $\mathrm{OR}^{\mathrm{c}}(95 \% \mathrm{Cl})$ & $\mathrm{OR}^{\mathrm{d}}(95 \% \mathrm{Cl})$ \\
\hline \multicolumn{5}{|l|}{ Occupation } \\
\hline White collar & 1.00 & 1.00 & 1.00 & 1.00 \\
\hline Mixed group & $1.53(1.19-1.54)$ & $1.44(1.09-1.89)$ & $1.47(1.10-1.95)$ & $1.39(1.04-1.87)$ \\
\hline Blue collar & $1.79(1.56-2.05)$ & $1.53(1.31-1.77)$ & $1.48(1.27-1.76)$ & $1.39(1.17-1.64)$ \\
\hline$p$-value for trend & $<0.001$ & $<0.001$ & $<0.001$ & $<0.001$ \\
\hline \multicolumn{5}{|l|}{ Education } \\
\hline High & 1.00 & 1.00 & 1.00 & 1.00 \\
\hline Middle & $1.60(1.35-1.89)$ & $1.38(1.15-1.66)$ & $1.29(1.07-1.55)$ & $1.20(0.99-1.46)$ \\
\hline Low & $1.96(1.56-2.47)$ & $1.51(1.17-1.95)$ & $1.41(1.09-1.83)$ & $1.31(1.00-1.70)$ \\
\hline \multirow[t]{3}{*}{$p$-value for trend } & $<0.001$ & 0.009 & 0.013 & 0.103 \\
\hline & WOMEN & & & \\
\hline & $\mathrm{OR}^{\mathrm{a}}(95 \% \mathrm{Cl})$ & $\mathrm{OR}^{\mathrm{b}}(95 \% \mathrm{Cl})$ & $\mathrm{OR}^{\mathrm{c}}(95 \% \mathrm{Cl})$ & $\mathrm{OR}^{\mathrm{d}}(95 \% \mathrm{Cl})$ \\
\hline \multicolumn{5}{|l|}{ Occupation } \\
\hline White collar & 1.00 & 1.00 & 1.00 & 1.00 \\
\hline Mixed group & $1.04(0.77-1.43)$ & $0.96(0.61-1.52)$ & $1.01(0.64-1.59)$ & $0.99(0.63-1.57)$ \\
\hline Blue collar & $0.94(0.75-1.94)$ & $0.96(0.74-1.23)$ & $0.99(0.77-1.27)$ & $0.96(0.74-1.25)$ \\
\hline$p$-value for trend & 0.752 & 0.995 & 0.994 & 0.958 \\
\hline \multicolumn{5}{|l|}{ Education } \\
\hline High & 1.00 & 1.00 & 1.00 & 1.00 \\
\hline Middle & $0.78(0.57-1.06)$ & $0.75(0.53-1.05)$ & $0.74(0.53-1.04)$ & $0.73(0.52-1.03)$ \\
\hline Low & $0.78(0.53-1.13)$ & $0.86(0.56-1.32)$ & $0.86(0.56-1.31)$ & $0.84(0.55-1.29)$ \\
\hline$p$-value for trend & 0.255 & 0.222 & 0.183 & 0.183 \\
\hline
\end{tabular}

aadjusted for 10-years age groups, country

badjusted for 10-years age groups, country, smoking pack-years

cadjusted for 10-years age groups, country, smoking pack-years, type of cigarettes/cigars

dadjusted for 10-years age groups, country, smoking pack-years, type of cigarettes/cigars, exposure to occupational carcinogens (exposure ever to inorganic insulation dust, all arsenic, abrasives dust, silica, carbon black dust, wood dust, chromate dust, cadmium fumes, PAHs)

Table 4. Association between socioeconomic status indicators and risk of lung cancer by smoking status in men

\begin{tabular}{|c|c|c|c|c|}
\hline & \multirow{2}{*}{$\begin{array}{l}\text { Never smokers } \\
\text { o pack-years }\end{array}$} & \multicolumn{3}{|c|}{ Ever smokers by smoking in pack-years } \\
\hline & & pack-years $\leq 18$ & $\begin{array}{l}\text { pack-years }>18 \text { \& pack- } \\
\text { years } \leq 33\end{array}$ & pack-years $>33$ \\
\hline & $\mathrm{OR}^{\mathrm{a}}(95 \% \mathrm{Cl})$ & $\mathrm{OR}^{\mathrm{a}}(95 \% \mathrm{Cl})$ & $\mathrm{OR}^{\mathrm{a}}(95 \% \mathrm{Cl})$ & $\mathrm{OR}^{\mathrm{a}}(95 \% \mathrm{Cl})$ \\
\hline \multicolumn{5}{|l|}{ Occupation } \\
\hline White collar & 1.00 & 1.00 & 1.00 & 1.00 \\
\hline Mixed group & $4.19(1.38-12.7)$ & $1.78(0.84-3.78)$ & $1.46(0.84-2.52)$ & $1.12(0.75-1.67)$ \\
\hline Blue collar & $2.51(1.09-5.76)$ & $1.90(1.19-3.02)$ & $1.41(1.04-1.91)$ & $1.15(0.91-1.47)$ \\
\hline \multicolumn{5}{|l|}{ Education } \\
\hline High & 1.00 & 1.00 & 1.00 & 1.00 \\
\hline Middle & $1.01(0.45-2.29)$ & $1.44(0.85-2.43)$ & $1.47(1.02-2.11)$ & $1.04(0.78-1.39)$ \\
\hline Low & $0.78(0.23-2.64)$ & $3.03(1.48-6.20)$ & $1.36(0.82-2.22)$ & $1.10(0.76-1.59)$ \\
\hline
\end{tabular}

aadjusted for 10-years age groups, country, exposure to occupational carcinogens (exposure ever to inorganic insulation dust, all arsenic, abrasives dust, silica, carbon black dust, wood dust, chromate dust, cadmium fumes, PAHs) 


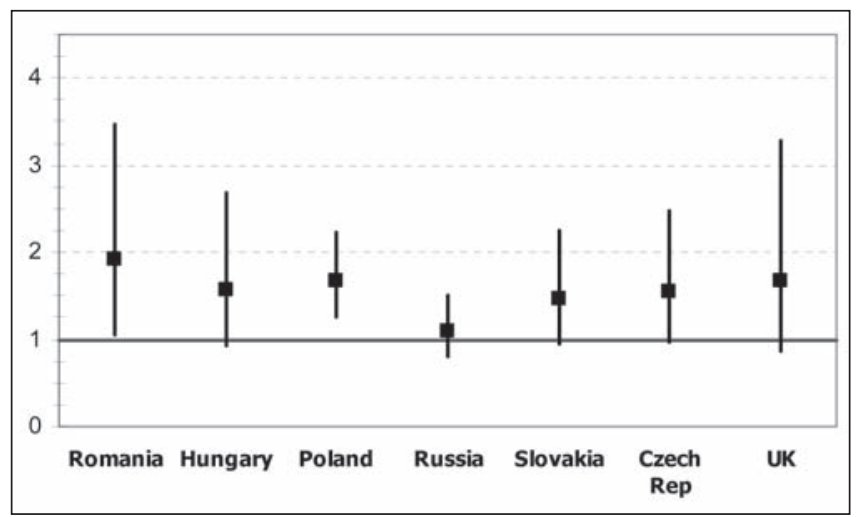

OR and $95 \% \mathrm{Cl}$ adjusted for smoking for blue collar workers compared to white collar workers

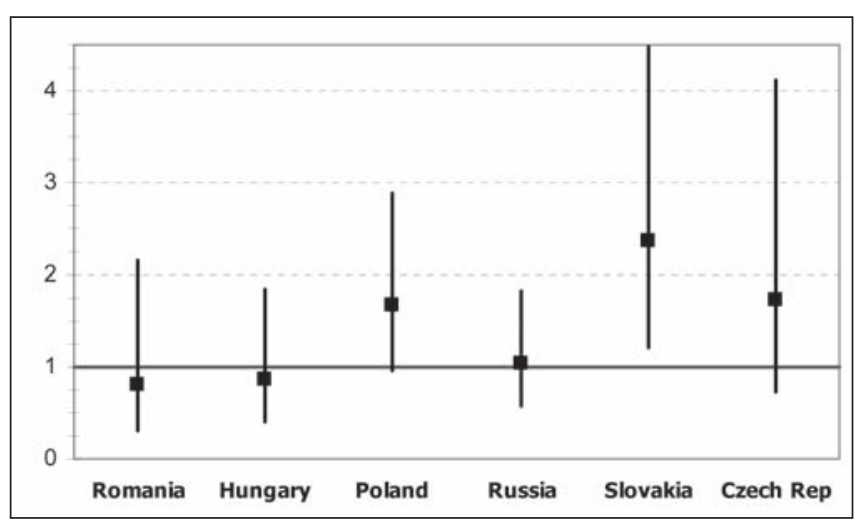

OR and $95 \% \mathrm{Cl}$ adjusted for smoking for low education compared to high education

Fig. 1. Association between socioeconomic status indicators and risk of lung cancer by countries in men

women among cases than among controls. Controls were better educated than cases, the difference being statistically significant in men but not in women. There was also a higher percentage of white collar workers among controls than among cases.

The distribution of cumulative tobacco consumption according to socioeconomic indicators in controls is shown in Table 2. Among male blue collar workers there were $20.3 \%$ nonsmokers and $31.3 \%$ heavy smokers, compared to $28.6 \%$ of nonsmokers and $22.4 \%$ heavy smokers in white collar workers $(\mathrm{p}<0.001)$. A similar trend was observed for education. Women with high education smoked more than women with low education $(\mathrm{p}<0.001)$, while no statistically significant differences were observed by the occupation-based indicator. Similarly, prevalence of occupational exposure to the selected set of carcinogens in male controls is significantly higher for blue collar workers (76.6\%) than for white collar workers (27.2\%), and also significantly higher for low education (72.5\%) than for high education (26.9\%). Similar significant differences were observed in women $(28.1 \%$ in blue versus $7.2 \%$ in white collar workers; $20.9 \%$ in low versus $8.8 \%$ in high education).

Table 3 shows adjusted OR of lung cancer related to socioeconomic indicators. Compared with white collar workers, the OR for blue collar workers in men adjusted for age and country was 1.79 (95\% CI 1.56-2.05). The OR remained significant after adjustment for smoking habits, and also after additional adjust- ment for occupational exposure to carcinogens. As for education in men, the OR for low education compared with high education was 1.96 (95\%CI 1.56-2.47). Similarly the OR remained significant after additional adjustments for smoking and occupational exposure to carcinogens. Similar negative association was found in middle education, where the OR was 1.60 (95\% CI 1.35-1.89). For women, no significant results were found. OR for occupation was close to 1 , and odds ratios for education were pointing to protective effect of middle and low educations, however, these were also not significant.

Results of effect of socioeconomic indicators on risk of lung cancer in men by smoking groups are shown in Table 4 . Results do not show consistent effect for never-smokers, where the OR for blue collar workers was 2.51 (95\% CI 1.09-5.76) but the OR for middle education was 1.01 (95\% CI 0.45-2.29) and the OR for low education was 0.78 (95\%CI 0.23-2.64). For ever-smokers by pack-years cigarettes smoked, results are consistent, showing similar significant negative effect for occupation-based indicator and education in all smoking categories. Stronger effect was found in light smokers, weaker effect in middle group of smokers and no effect in heavy smokers. Test of interactions between occupationbased indicator and smoking showed borderline non-significance $(p=0.053)$, test of interactions between education and smoking was found significant $(\mathrm{p}=0.026)$.

Analyses by countries are shown in Fig. 1 . Results show consistent negative effect of socioeconomic indicators. Results confirmed negative associations between occupation-based indicators and risk of lung cancer in men from data for centres in Romania (OR for blue collar compared to white collar occupation 1.73 95\% CI 1.02-2.93), Poland (OR 2.06; 95\% CI 1.59-2.66), Slovakia (OR 2.26 95\% CI 1.56-3.26), Hungary (OR 2.09 95\% CI 1.30-3.38), and the Czech Republic (OR 1.82 95\% CI 1.22-2.71). However after adjustment for smoking, the only significant OR was found in data for Romania (OR 1.91 95\% CI 1.06-3.46) and Poland (OR 1.67 95\% CI 1.26-2.23). Similarly for education, significant negative associations were found in Poland (OR 2.05 95\% CI 1.27-3.31), Slovakia (OR 3.30 95\% CI 1.88-5.80), and the Czech Republic (OR 3.23 95\% CI 1.53-6.83). After adjustment for smoking, the association remained significant only for data from centres in Slovakia (OR 2.36 95\% CI 1.21-4.59). Testing of interactions between both socioeconomic indicators and country in men did not confirm heterogeneity (white/blue collar worker and country in men: $p=0.607$, education and country in men: $p=0.288$ ).

Analysis of effects of socioeconomic indicators on lung cancer development in women was consistent, showing no effect in Central European countries. The only significant negative association was found in the UK data (OR for blue collar compared to white collar workers 2.85; 95\% CI 1.37-5.95), which did not remain significant after adjustment for smoking (adjusted OR 1.54; 95\% CI 0.67-3.56). As for education, results were not significant except for the data in Russia, where an opposite effect was seen (OR for low compared to high education 0.10 ; 95\% CI 0.03-0.57, OR after adjustment for smoking 0.14 ; 95\% CI 0.03-0.60).

\section{DISCUSSION AND CONCLUSIONS}

By Krieger (16), social class refers to social group arising from interdependent economic relationship among people, and 
socioeconomic position is an aggregate concept that includes both resource-based and prestige-based measures, as linked both childhood and adult social class position. Considering that most of the study participants lived majority of their lives during socialist period, socioeconomic status indicators connected with occupation and education were mainly related to family and/or community prestige, life-style and activities during free time, habits and nutrition. Higher education and/or white collar occupations were associated with healthier life style, healthier free-time activities, and healthier habits and nutrition.

For determination of occupation-based socioeconomic indicator in our study, life/time history of occupations coded by ISCO was used. In recent studies last occupation (4), usual occupation (10), occupation at several career points (7) and also occupational history $(6,9)$ were used. Overview of used measures was published elsewhere (18). Advantages of using this type of proxy are the individual evaluation, the possibility of verification, the coding precision. A main disadvantage is the direct relation between an occupation and connected occupational exposure to carcinogens. Education systems in Central European countries were similar, so the indicator with three categories could be constructed: low, middle and higher education. Due to differences in educational system, data from the UK were excluded from the analyses.

When analyzing association between socioeconomic indicators and risk of lung cancer, two main issues appear: indicators of occupation are related to smoking habits, and also to occupational exposure to carcinogens $(6,12,18-20)$. An unbalanced distribution of tobacco use among social classes is expected, with most common use among lower social class urban men and women (9). This was confirmed in this study for men only (Table 2), having the opposite gradient in the female smoking proportions, when low educated women smoke significantly less than high educated women (e.g. proportions of ever smokers were $20.6 \%$ for low and $36.3 \%$ for high education). Both socioeconomic indicators were in this study strongly related to occupational exposure to carcinogens.

We investigated the relationship between these two indicators of socioeconomic status (occupation-based and education) and risk of lung cancer. For adjustment of the effect of tobacco smoking we used three proxies. For adjustment of the effect of occupational exposure to carcinogens, the set of carcinogens was selected based on data analyses from this study, as the exposures having the strongest effects on lung cancer development. Our findings are $39 \%$ increase in risk of lung cancer for blue collar workers compared to white collar workers, and 31\% increase in risk of lung cancer for low education compared to high education in men, both after adjustment for effects of smoking and occupational exposure to carcinogens. Similar results were found for manual compared to non-manual men in the Renfrew/Paisley study (adjusted RR 1.27) and the Collaborative study (adjusted RR 1.24) (10). Relative risk of lung cancer in lower middle class compared to upper class adjusted to smoking habits was 2.7 (95\% CI 1.4-5.0) in the Copenhagen Male Study (12). Compared to social class I, men in social class IV and V had a significantly elevated risk of lung cancer, with OR respectively of 1.5 (95\% CI 1.1-2.3) and 1.9 (95\% CI 1.3-3.0) by results from the National Enhanced Surveillance in Canada (9).

To assess an influence of residual confounding of smoking, we also have studied association between socioeconomic indicators and risk of lung cancer in the different smoking categories. We found inconsistent effect of social indicators in never smokers: indicator of social class based on lifetime occupations had a very strong effect on risk of lung cancer development (OR 2.51; 95\% CI 1.09-5.76), but education did not show any effect (OR 0.78; 95\% CI 0.23-2.64). Results for ex-smokers and smokers are similar as in the other studies (in the study in Canada (9), OR 2.5 (95\% CI 1.4-4.4) for lowest social class compared with highest social class in ex-smokers, and OR 1.7 (95\% CI 0.8-3.6) in current smokers, similar to the observed trend by education in smokers in the study in the Netherlands (4) and in Finland (11)). In never smokers, no association between socioeconomic status indicators and risk of lung cancer was found in the previous studies (9).

We did not find any clear relationship between socioeconomic status indicators and lung cancer risk in women. The uniform behaviours of women, such as household and family care, maternity tasks, were dominant in all educational groups. Almost all women were employed in the Central European countries (21). However, their exposures as blue collar workers have different meaning as blue collar worker exposures in men, considering also much smaller percentage of women exposure to carcinogens, lesser physical strain. According to this data, low educated women smoke less than women with higher education, and blue collar female workers smoke less than white collar female workers. All these facts and factors could explain the observed lack of difference in risk of lung cancer.

When trying to explain the different pattern in lung cancer risk for men and women, some facts have to be taken into account: high lung cancer incidence rates in men (65.7/100,000 Eastern Europe) versus low incidence of lung cancer in women (8.7/100,000 Eastern Europe) (22). Employment under health risk conditions is more frequent for men than for women, e.g. in Slovakia $75 \%$ of risk jobs are performed by men and $25 \%$ by women (23). Men are dominantly employed in the traditional men professions (construction, mining, heavy industry) (24). Occupational diseases are mainly identified and confirmed in men, e.g. in Slovakia $70 \%$ of all occupational diseases have been identified and compensated in men and all occupational lung cancer ever have been confirmed only in men (25). Men's life expectancies are 6 to 13 years lower than women's ones in the studied Central European countries and Russia (26). The difference is growing in time, as it was about 4 years in 1950. Smoking behaviour in men and women is also different, with higher prevalence of smokers in men than in women, as it was confirmed in our study and elsewhere $(27,28)$.

Possible limitation of these analyses is no adjustment to environmental conditions including air pollution $(29,30)$. Influence of residual confounding of smoking remained unexplained as well, alike as a possible other individually important occupational exposure to other carcinogens. Estimates of effects of socioeconomic indicators substantially lowered after additional adjustments to smoking proxies, effect found in a smaller group of never smokers was inconsistent.

We suggest that the significant inverse association between socioeconomic indicators and risk of lung cancer in men may serve as an incentive in lung cancer prevention. Socioeconomic indicators as blue collar worker and/or low education in connection with smoking habits altogether indicate possible higher risk for lung cancer development. 


\section{Acknowledgments}

Financial support by a grant from the European Commision's INCOCopernicus Programme (Contract No. IC 15-CT96-0313) is gratefully acknowledged. This work has been also supported by a UICC International Cancer Technology Transfer Fellowship.

\section{REFERENCES}

1. European Communities; World Health Organisation. Health status overview for countries of Central and Eastern Europe that are candidates for accession to the European Union. Copenhagen: WHO; 2002.

2. Brennan P, Crispo A, Zaridze D, Szeszenia-Dabrowska N, Rudnai P, Lissowska J, et al. High cumulative risk of lung cancer death among smokers and non-smokers in Central and Eastern Europe. Am J Epidemiol. 2006 Dec 15;164(12):1233-41

3. Faggiano F, Partanen T, Kogevinas M, Boffetta P. Socioeconomic differences in cancer incidence and mortality. In: Kogevinas M, Pearce N, Susser M, Boffetta P, editors. Social inequalities and cancer. IARC Scientific Publications no. 138. Lyon: International Agency for Research on Cancer; 1997. p. 65-176

4. Van Loon AJ, Goldbohm RA, van den Brandt PA. Lung cancer: is there an association with socioeconomic status in The Netherlands? J Epidemiol Community Health. 1995 Feb;49(1):65-9.

5. Bucher HC, Ragland DR. Socioeconomic indicators and mortality from coronary heart disease and cancer: a 22-year follow-up of middle-aged men. Am J Public Health. 1995 Sep;85(9):1231-6.

6. Van Loon AJ, Goldbohm RA, Kant IJ, Swaen GM, Kremer AM, van den Brandt PA. Socioeconomic status and lung cancer incidence in men in The Netherlands: is there a role for occupational exposure? J Epidemiol Community Health. 1997 Feb;51(1):24-9

7. Marshall B, Chevalier A, Garillon C, Goldberg M, Coing F. Socioeconomic status, social morbidity and cancer occurrence during working life: a case-control study among French electricity and gas workers. Cance Causes Control 1999 Dec;10(6):495-502.

8. Merler E, Benvenuti A, Baldi P, Nardulli MC, Olmastroni L, Biggeri A, et al. Socioeconomic inequalities in health in the Tuscany Longitudina Study SLTO: persistence and changes over time in overall mortality and selected causes (lung cancer, liver cirrhosis, AIDS and overdose). Epidemiol Prev. 1999 Jul-Sep;23(3):207-14. (In Italian.)

9. Mao Y, Hu J, Ugnat AM, Semenciw R, Fincham S; Canadian Cancer Registries. Socioeconomic status and lung cancer risk in Canada. Int J Epidemiol. 2001 Aug;30(4):809-17.

10. Hart CL, Hole DJ, Gillis CR, Smith GD, Watt GC, Hawthorne VM. Socia class differences in lung cancer mortality: risk factor explanations using two Scottish cohort studies. Int J Epidemiol. 2001 Apr;30(2):268-74.

11. Martikainen P, Lahelma E, Ripatti S, Albanes D, Virtamo J. Educational differences in lung cancer mortality in male smokers. Int J Epidemiol. 2001 Apr;30(2):264-7.

12. Hein HO, Suadicani P, Gyntenberg F. Lung cancer risk and social class. The Copenhagen Male Study - 17-year follow up. Dan Med Bull. 1992 Apr;39(2):173-6
13. Kogevinas M, Pearce N, Susser M, Boffetta P, editors. Social inequalities and cancer. IARC Scientific Publications no. 138. Lyon: International Agency for Research on Cancer; 1997.

14. International Labour Office. International standard classification of occupations. Rev ed 1968. Geneva: ILO; 1968.

15. StataCorp. Stata statistical software: release 8.2. College Station: Stata Corporation; 2004.

16. Krieger N. Glossary for social epidemiology. J Epidemiol Community Health. 2001 Oct;55(10):693-700.

17. Mackenbach JP, Kunst AE. Measuring the magnitude of socioeconomic inequalities in health: an overview of available measures illustrated with two examples from Europe. Soc Sci Med. 1997 Mar;44(6):757-71.

18. Boffetta P, Westerholm P, Kogevinas M, Saracci R. Exposure to occupational carcinogens and social class difference in cancer occurrence. In Kogevinas M, Pearce N, Susser M, Boffetta P, editors. Social inequalities and cancer. IARC Scientific Publications no. 138. Lyon: International Agency for Research on Cancer; 1997. p. 331-43.

19. Pukkala E. Cancer risk by social class and occupation. Contributions to Epidemiology and Biostatistics vol. 7. Basel: Karger; 1995.

20. Bouchardy C, Schüler G, Minder C, Hotz P, Bousquet A, Levi F, et al Cancer risk by occupation and socioeconomic group among men - a study by the Association of Swiss Cancer Registries. Scand J Work Environ Health. 2002;28 Suppl 1:1-88.

21. Lupri E, editor. The changing position of women in family and society: a cross-national comparison. Leiden: E.Brill; 1983.

22. Parkin DM, Bray F, Ferlay J, Pisani P. Global cancer statistics, 2002. CA Cancer J Clin. 2005 Mar-Apr;55(2):74-108

23. Employment in Europe 2005. EU Labour Force Survey and National Account. Brussels: Eurostat.

24. Fabianová E. Preventive occupational medicine today and tomorrow. Čes Prac Lék. 2006;7(3):137-9. (In Slovak.)

25. Health statistics yearbook of the Slovak Republic 2003. Bratislava: Institute of Health Information and Statistics; 2004.

26. WHO Regional Office for Europe [homepage on the Internet]. European health for all database (HFA-DB) [cited 2008 Oct 5]. Available from: http://www.euro.who.int/hfadb.

27. Sovinová H, Sadílek P, Czémy L. Development of smoking prevalence in the Czech adult population. Prague: National Institute of Public Health; 2007. (In Czech.)

28. Avdičová M, Hrubá F, Herdová O, Námešná J, Francisciová K. Health habits and the health quality of the adult population in Slovakia in the year 2002. Banská Bystrica: State Public Health Institute; 2003.

29. Siemiatycki J, Wacholder S, Dewar R, Cardis E, Greenwood C, Richardson L. Degree of confounding bias related to smoking, ethnic group and socioeconomic status in estimates of the association between occupation and cancer. J Occup Med. 1988 Aug;30(8):617-25.

30. Barbone F. Bovenzi M, Cavallieri F, Stanta G. Air pollution and lung cancer in Trieste, Italy. Am J Epidemiol. 1995 Jun 15;141(12):1161-9.

Received September 5, 2008 Accepted in revised form February 24, 2009 